\title{
Using the Theory of Planned Behaviour to Predict Purchase Intention towards using Taobao
}

\author{
Juwairiah Haris, Suzari Abdul Rahim, Munirah Haris, Mohd Shahir Zahari
}

To Link this Article: http://dx.doi.org/10.6007/IJARBSS/v11-i2/9191 DOI:10.6007/IJARBSS/v11-i2/9191

Received: 19 December 2020, Revised: 20 January 2021, Accepted: 01 February 2021

Published Online: 27 February 2021

In-Text Citation: (Haris et al., 2021)

To Cite this Article: Haris, J., Rahim, S. A., Haris, M., \& Zahari, M. S. (2021). Using the Theory of Planned Behaviour to Predict Purchase Intention towards using Taobao. International Journal of Academic Research in Business and Social Sciences, 11(2), 952-959.

Copyright: (c) 2021 The Author(s)

Published by Human Resource Management Academic Research Society (www.hrmars.com)

This article is published under the Creative Commons Attribution (CC BY 4.0) license. Anyone may reproduce, distribute, translate and create derivative works of this article (for both commercial and non-commercial purposes), subject to full attribution to the original publication and authors. The full terms of this license may be seen

at: http://creativecommons.org/licences/by/4.0/legalcode

Vol. 11, No. 2, 2021, Pg. 952 - 959

http://hrmars.com/index.php/pages/detail/IJARBSS

JOURNAL HOMEPAGE

Full Terms \& Conditions of access and use can be found at http://hrmars.com/index.php/pages/detail/publication-ethics 


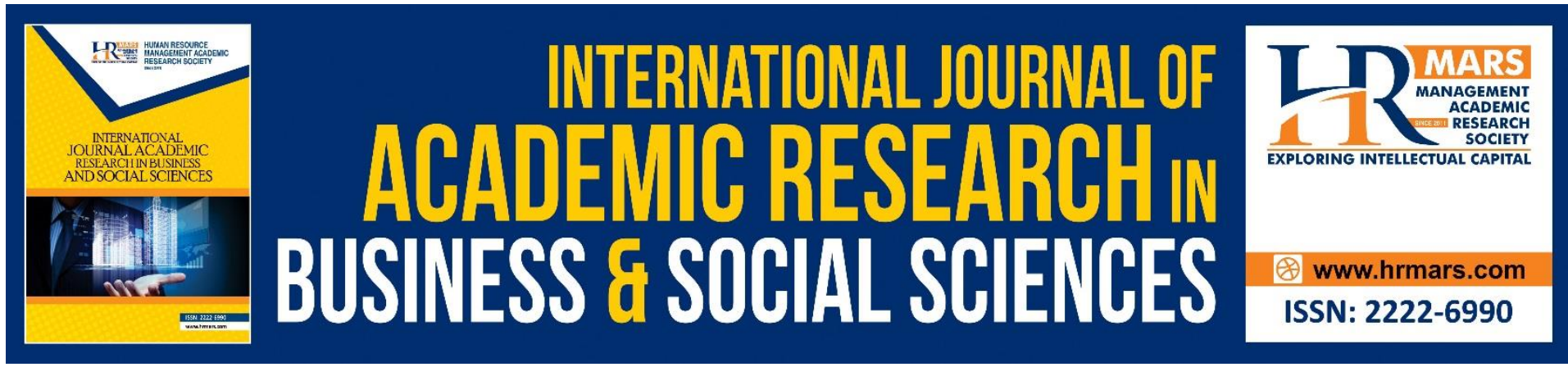

\title{
Using the Theory of Planned Behaviour to Predict Purchase Intention towards using Taobao
}

\author{
Juwairiah Haris, Suzari Abdul Rahim \\ Universiti Sains Malaysia, Malaysia \\ Munirah Haris \\ MRSM Kubang Pasu, Malaysia \\ Mohd Shahir Zahari \\ Kolej Vokasional Seberang Perai, Malaysia
}

\begin{abstract}
The Internet has witnessed a rapid growth in the development of e-commerce market. Taobao, for example, is one of the fastest-growing e-commerce sites that has received increasing attention from online retailers as a promising e-commerce market in the world. Given the rapid growth of the e-commerce market, there is a necessity to understand consumers' e-commerce behaviour towards the platform usage. This study attempts to examine consumers' online purchasing behaviour in e-commerce platform. As proposed by the Theory of Planned Behaviour (TPB), consumers' purchase intentions are affected not only by their attitudes, but also by their group's influences and their own perceived control. Therefore, in this study, attitude, subjective norm, and perceived behavioral control as the main constructs of the TPB are examined to predict purchase intention of micro-businesses in Malaysia. Research findings indicate that attitude and subjective norms are statistically significant determinants for respondents' purchase intention towards purchasing behaviour using Taobao. The results provide insights for micro-businesses in Malaysia who have the intention to purchase in Taobao to see it as a potential platform in search of eligible suppliers and purchase their product sourcing. Future research should explore supplier selection behaviour from the perspective of other stakeholders and from the e-commerce seller internal level. Also, other possible aspects such as gender-based perspective should also be considered as an added value for this research.
\end{abstract}

Keywords: E-Commerce, Purchase Intention, Purchase Behaviour, Theory of Planned Behaviour (TPB)

\section{Introduction}

The emergence of e-commerce has revolutionarily brought people to a whole new era of business. This new trend of business is well-received and growing rapidly in many places around the world today, observing global consumers' shift of preference to online shopping as well as showing the growth of market sharing. One of the most popular retail e-commerce 
sites today is Taobao which is operated in China by Alibaba Group and becomes a major online marketplace with market share over $80 \%$ (Davis, 2014). Taobao marketplace provides a platform for small- and medium-sized companies to open online stores and put products and descriptions like a typical physical store. Offering full-service strategy without charging money to sellers for using the platform, along with additional features such as free instant message tool, made Taobao grown remarkably fast since founded in 2003 (Ignatius, 2009).

As a dominant e-commerce site with more than 8 million vendors, Taobao ripe with opportunities attracting many micro- and small- businesses as well as individual entrepreneurs to sell and purchase products on the website (Mozur, 2014). Possessing the nature of e-commerce, Taobao provides benefits in which people can purchase products anywhere at any time, convenience, and ese of access. Using Taobao, vendors can create their own stores that are consistent over time, consumers also might develop a preference for a certain store from which they would have intention to buy things frequently.

Nevertheless, contrary to the growing number of online vendors, consumers' perceptions and attitudes towards Taobao are not always positive. There is a widespread concern about the trust towards Taobao and other online shopping platforms in China. Like other e-commerce sites, Taobao induces concerns and risk perceptions among consumers about possible losses, such as money, security, delivery time, or the product itself (Chen \& Dubinsky, 2003; Liebermann \& Stashevsky, 2002). The perceived risk of online shopping always exists to some extent across e-commerce marketplaces due to its nature, in particular, when consumers need to make transactions without having the chance to physically examine the products (Kim, Ferrin \& Rao, 2008).

Therefore, this paper is going to examine consumers' purchase intention in using Taobao as a platform to purchase product and choosing suppliers. This is done by applying the general framework of the Theory of Planned Behaviour (Ajzen, 1991) in examining how attitudes, perception and social expectation could potentially motivate Malaysia micro-businesses' intention into using Taobao marketplace in search of suppliers and purchase their product. TPB helps to understand the structure of retailer-customer relationships which leads to behavioural norms and expectations to eventually predict behaviour (Potdar, Guthrie, \& Gnoth, 2018). By scrutinizing respondents' perspectives towards Taobao will help to provide a better, clearer picture to micro-businesses in Malaysia in using e-marketplace platform such as Taobao in their search of supplier.

\section{Literature Review}

The Theory of Planned Behaviour (TPB), proposed by Ajzen (1985), is a social cognitive model used in social psychology to explain the complexity of human behaviour in terms of rational decision making. This theory believes that individual's intention is the most suitable predictive variable to explain behaviour. The intention reflects motivations and cognitive planning for engaging in the behaviour, as is determined by three key cognitive factors which are attitude, subjective norm, and perceived behavioural control. In general, the more positive the individual's attitude and subjective norm about behaviour, the stronger the control of perceptual behaviour, the stronger the individual's will to choose and implement the behaviour. 
TPB has been the basis for several studies of online purchasing and selection behaviour (Battacherjee, 2000; George, 2004; Limayem et al., 2000; Pavlou, 2003; Suh \& Han, 2003). In the current study, the study adopted the TPB model (Ajzen, 1991) as a theoretical framework to predict purchase intention and behaviour among Malaysian micro-businesses in using Taobao.com (Taobao) as a platform in search for supplier and product sourcing. The researcher believes that TPB could provide a theoretical basis for understanding the microbusinesses behaviour of selecting supplier. This study believes that the three predictive variables affect the behavioural intention of micro-businesses, and then influence their behaviour in selecting supplier (i.e. purchase behaviour in Taobao). Thus, the interpretation of the TPB-based micro-businesses behaviour is feasible.

Within the TPB, the first construct, attitude, refers to the degree of favourable or adverse evaluations of the behavioural consequences (Ajzen \& Fishein, 1980). The evaluation is subjective which could result to a negative or positive outcome (Eagly \& Chaiken, 1993). Individual's attitude towards certain behaviour is an immediate antecedent that predicts their intention to engage in certain behaviours (Ajzen, 1985). Therefore, in this study the attitude of micro-business towards using Taobao entails a consideration of the outcomes of performing the actual behaviour of selecting supplier and purchasing their product in Taobao.

The second construct in the TPB is the social situational factor, that is subjective norms, which is the social pressure or expectation of others that individuals feel when they choose to implement or not to conduct a specific behaviour (Fishbein \& Ajzen, 1975). Subjective norms describe the belief about whether other important people approve or disapprove a certain behaviour (Ajzen \& Fishein, 1980). In the context of this study, family, friends as well as societal demands and pressures are major determinants of micro businesses' preference that determine the micro-businesses' behavioural intentions of using Taobao in selecting their supplier.

The third construct in TPB, perceived behavioural control, can be described as an individual's perception of the level of ease or difficulty in performing or conducting the required behaviour of interest (Ajzen, 1991). In other words, perceived behavioural control is related to the individual's belief of their ability to execute the behaviour. Typically, it varies in different circumstances, which results in the individual having fluctuating perceptions of behavioural control depending on the context. In this study, micro businesses' perception of ease or difficulty to use Taobao in search of the right supplier is crucial in determining the actual behaviour of the choosing the supplier for their company.

In testing the basic TPB model, it is assumed that all relationships within TPB are significantly positive, which are confirmed by previous empirical research studies (Ajzen, 1991; Fishbein \& Ajzen, 1975). More specifically, the following relationships are expected to be:

H1: Attitude towards purchasing in Taobao has a positive relationship with purchase intention.

$\mathrm{H} 2$ : Subjective Norms towards purchasing in Taobao has a positive relationship with purchase intention. 
H3: Perceived Behavioural Control towards purchasing in Taobao has a positive relationship with purchase intention.

H4: Purchase Intention has a positive relationship with purchase behaviour.

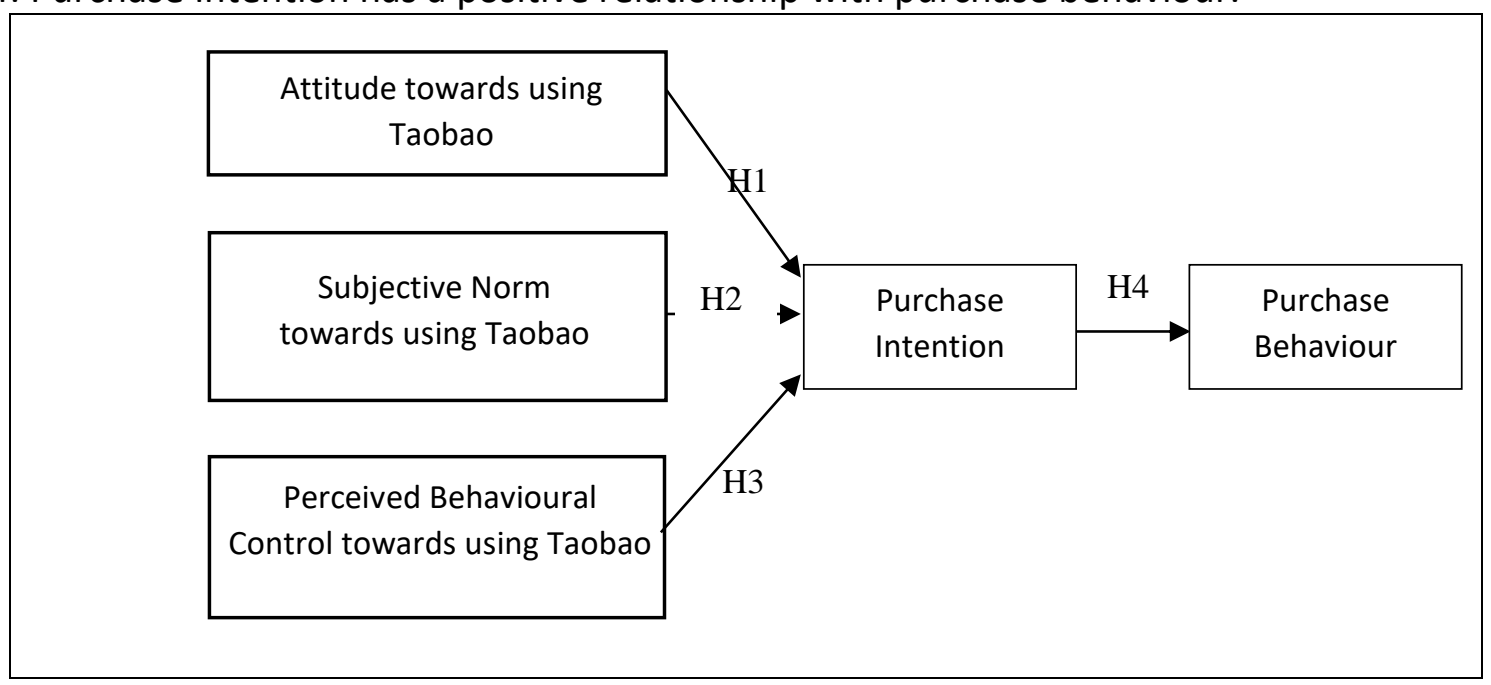

Figure 1. Conceptual Research Framework

\section{Methodology}

In this study, the questionnaire method was used to collect the data. The data was collected using purposive sampling and analysed using Statistical Package for the Social Science (SPSS) and Partial Least Squares Structural Equation Modelling (PLS SEM). A total of 250 questionnaires were issues, however 129 were withdrawn. Only 100 valid questionnaires were obtained. The questionnaire used the five-point Likert scales. Each item ranges from 1 (strongly disagree) to 5 (strongly agree). The survey was conducted to people who run the business. As shown in Table 1, majority of the sellers are female (57\%) with range of age between 21 to 30 years old (43\%).

Table 1. Demographic of Respondents

\begin{tabular}{|l|c|c|}
\hline Items & Characteristic & Frequency \\
\hline \multirow{4}{*}{ Gender } & Male & 31 \\
\hline \multirow{4}{*}{ Age } & Female & 69 \\
\cline { 2 - 3 } & 20 and below & 18 \\
\cline { 2 - 3 } & $21-30$ & 43 \\
\cline { 2 - 3 } & $31-40$ & 24 \\
\cline { 2 - 3 } & 41 and above & 15 \\
\hline \multirow{3}{*}{ Experiences } & Less than 1 year & 27 \\
\cline { 2 - 3 } & $1-5$ year & 51 \\
\cline { 2 - 3 } & $6-10$ year & 21 \\
\cline { 2 - 3 } & 11 and above & 1 \\
\hline
\end{tabular}

\section{Result and Discussion}

According to Hair et al., (2009; 2014), if the items consist of two or more loading variable greater than .5, it shows that the items obtain significant cross loadings. Referring to Hair et al., (2016), AVE should be above 0.5 in order to attain convergent validity. Hair et al., (2014; 2016) also stated that CR value should greater than 0.7 to confirm internal consistency of the 
construct. The model tested consisted of 18 items. The result shows that all items have strongest interaction factor loading, attain convergent validity and reliability for internal consistency. Table 2 presents the results of factor loading, AVE and CR.

Table 2. The Results of Factor Loading, AVE and CR

\begin{tabular}{|c|c|c|c|c|}
\hline Factor & Items & Loading & AVE & CR \\
\hline \multirow[t]{3}{*}{ Attitude } & ATT1 & 0.921 & \multirow[t]{3}{*}{0.863} & \multirow[t]{3}{*}{0.949} \\
\hline & ATT2 & 0.923 & & \\
\hline & ATT3 & 0.942 & & \\
\hline \multirow[t]{4}{*}{ Perceived Behavioural Control } & PBC1 & 0.794 & \multirow[t]{4}{*}{0.640} & \multirow[t]{4}{*}{0.844} \\
\hline & PBC2 & 0.853 & & \\
\hline & PBC3 & 0.792 & & \\
\hline & PBC4 & 0.758 & & \\
\hline \multirow[t]{4}{*}{ Subjective Norm } & SN1 & 0.815 & \multirow[t]{4}{*}{0.664} & \multirow[t]{4}{*}{0.885} \\
\hline & SN2 & 0.884 & & \\
\hline & SN3 & 0.818 & & \\
\hline & SN4 & 0.735 & & \\
\hline \multirow[t]{4}{*}{ Behavioural Intention } & INT1 & 0.812 & \multirow[t]{4}{*}{0.791} & \multirow[t]{4}{*}{0.936} \\
\hline & INT2 & 0.891 & & \\
\hline & INT3 & 0.922 & & \\
\hline & INT4 & 0.927 & & \\
\hline \multirow[t]{3}{*}{ Supplier Selection Behaviour } & BEH1 & 0.769 & \multirow[t]{3}{*}{0.682} & \multirow[t]{3}{*}{0.866} \\
\hline & $\mathrm{BEH} 2$ & 0.890 & & \\
\hline & $\mathrm{BEH} 3$ & 0.814 & & \\
\hline
\end{tabular}

Table 3 below shows a total of four hypotheses that were tested and the results supported three of the proposed hypotheses. The results indicated that $\mathrm{H} 1, \mathrm{H} 2$ and $\mathrm{H} 4$ are statistically significant at $\mathrm{p}$ value $<.001$. this study found that $\mathrm{H} 1$ (attitude towards purchasing in Taobao influence purchase intention) has a $\beta$ value of 0.116 and t-value $3.436^{* * *}$, followed by $\mathrm{H} 2$ (subjective norm towards purchasing in Taobao influence purchase intention) with a $\beta$ value of 0.084 and t-value $3.855^{* * *}$. Next is $\mathrm{H} 4$ (purchase intention influence purchase behaviour in Taobao) has a $\beta$ value of 0.060 and $t$-value $11.951^{* * *}$. On the other hand, $\mathrm{H} 3$ (perceived behaviour control towards purchasing in Taobao influence purchase intention) is statistically insignificant at $p$ value $(\beta=0.104$, t-value 1.609), therefore $H 3$ is not supported.

Table 3. Results of the study

\begin{tabular}{|l|l|l|l|l|l|l|l|}
\hline & & VIF & F2 & Beta & T value & P value & Result \\
\hline H1 & ATT -> INT & 2.098 & 0.108 & 0.116 & $3.436^{* * *}$ & 0.000 & Significant \\
\hline H2 & SN -> INT & 1.765 & 0.086 & 0.084 & $3.855^{* * *}$ & 0.000 & Significant \\
\hline H3 & PBC -> INT & 1.944 & 0.020 & 0.104 & 1.609 & 0.054 & Not Significant \\
\hline H4 & INT -> BEH & 1.000 & 1.062 & 0.060 & $11.951^{* * *}$ & 0.000 & Significant \\
\hline
\end{tabular}

\section{Conclusion}

The findings in this study show that attitude and subjective norm are significant in influencing purchase intention toward using Taobao as a platform for micro-businesses in Malaysia to search for suppliers and purchase their product supplies. Much of the value from this study is 
to provide knowledge to micro-businesses in Malaysia with practical information when they have the intention to purchase in Taobao. As a business grow, different solutions are required to embrace problems and opportunities. The information provided by this study would enhance the understanding from TPB perspective that could encourage appropriate action for micro-businesses' side. This implies that, to achieve competitive advantage over the competitors, attitude and subjective norm from micro-businesses are important if sellers plan to use Taobao during the process of supplier selection.

Each study has its own constraints, this study offers fresh results and forms the basis on future works. Even so, majority of the respondents in this study are female and referring to Costa et al., (2001) who revealed in their study that personality between gender is genetically and culturally different. Hence, in a research, female respondents are more likely to possess perceptual attribute of agreeable than their male counterparts (Bernardino, Freitas \& Cadima, 2018). Therefore, future research should utilize equal number of respondents for both gender and scrutinize the sample studies according to gender-based perspective. Also, future research should explore supplier selection behaviour from the perspective of other stakeholders and from the e-commerce seller internal level.

\section{Acknowledgement}

We would like to extend our gratitude to the people involved in conducting this study. Deepest appreciation to the faculty and university for the trust given as well as thanks to our family and friends who have supported us all this time.

\section{Corresponding Author}

Juwairiah binti Haris

Graduate School of Business, Universiti Sains Malaysia, Malaysia.

Email: shahriah86@gmail.com

\section{References}

Ajzen, I. (1985). From intentions to actions: A theory of planned behavior. In J. Kuhl \& J. Beckman (Eds.), Action-control: From cognition to behavior. Heidelberg: Springer.

Ajzen, I. (1991). The theory of planned behaviour. Organizational Behaviour and Human Decision Processes, 50, 179-211.

Ajzen, I., \& Fishbein, M. (1980). Understanding Attitudes and Predicting Social Behavior. Prentice-Hall, Englewood Cliffs, NJ.

Battacherjee, A. (2000). Acceptance of e-commerce services: the case of electronic brokerages. IEEE Transactions on Systems, Man, and Cybernetics - Part A: Systems and Humans, 30(4), 411-420.

Bernardino, S., Freitas, S. J., \& Cadima, R. J. (2018). Social entrepreneur and gender: What's personality got to do with it? International Journal of Gender and Entrepreneurship, 10(1), 61-82.

Chen, Z., \& Dubinsky, A. J. (2003). A conceptual model of perceived customer value in ecommerce: A preliminary investigation. Psychology \& Marketing, 20(4), 323-347.

Costa, P., \& Terracciano, A., \& Mc Crae, R. R. (2001). Gender Differences in Personality Traits Across Cultures: Robust and Surprising Findings. Journal of personality and social psychology, 81, 322-31.

Davis, D. (2014). Alibaba values itself at \$130 Billion, Internet Retailer. Retrieved 2020, Jun 27 from https:// www.internetretailer.com/2014/07/14/alibaba-values-itself-130-billion 
Eagly, A. H., \& Chaiken, S. (1993). The Psychology of Attitudes. Harcourt Brace Jovanovich, Orlando, FL.

Fishbein, M., \& Ajzen, I. (1975). Belief, attitude, intention and behaviour: An introduction to theory and research. Reading, MA: Addison Wesley.

George, J. F. (2004). The theory of planned behavior and Internet purchasing. Internet Research, 198 - 212.

Hair, J. F., Hult G, T. M., Ringle , C., \& Sarstedt, M. (2014). A primer on partial least squares structural equation modeling (PLS-SEM). Thousand Oaks, CA: Sage Publications Incorporated.

Hair, J., Black, W., Babin, B., \& Anderson, R. (2009). Multivariate data analysis. Upper Saddle River, NJ: Prentice Hall.

Hair, J., Sarstedt, M., Matthews, L., \& Ringle, C. (2016). Identifying and treating unobserved heterogeneity with FIMIX-PLS: part I - method. European Business Review, 28(1), 6376.

Ignatius, A. (2009). Builders \& Titans: Jack Ma. Retrieved 2020, Jun 27 from Time Specials: http://www.time.com/time/specials/packages/article/0,28804,1894410_1893837_1 $894188,00 . \mathrm{html}$

Kim, D., Ferrin, D., \& Rao, H. (2008). A trust-based consumer decision making model in electronic commerce: The role of trust, perceived risk, and their antecedents. Decision Support System, 44(2), 544-564.

Liebermann, Y., \& Stashevsky, S. (2002). Perceived risks as barriers to Internet and ecommerce usage. Qualitative Market Research: An International Journal, 5(4), 291300.

Limayem, M., Khalifa, M., \& Frini, A. (2000). What Makes Consumers Buy from Internet? A Longitudinal Study of Online Shopping. IEEE Transaction on System, Man and Cybernetics- Part A: Systems and Humans, 30(4), 421-432.

Mozur, P. (2014). Alibaba: No deal on details for Taobao, Tmall. The Wall Street Journal. Retrieved 2020, Jun 28 from Retrieved from http://blogs.wsj.com/digits/ 2014/05/06 /quick-hit-on-alibabas-taobaotmall/

Pavlou, P. (2003) Consumer acceptance of electronic commerce: Integrating trust and risk with the technology acceptance model. International Journal of Electronic Commerce, 7(3), 101-134.

Potdar, B., Guthrie, J., \& Gnoth, J. (2018). Encouraging shoplifting prevention with quality relationships: A theory of planned behaviour perspective. International Journal of Retail \& Distribution Management, 46(1), 49-69.

Suh, B., \& Han, I. (2003). The impact of customer trust and perception of security control on the acceptance of electronic commerce. International journal of electronic commerce, $7(3), 135-61$. 